\title{
Identification of microRNA-Associated-ceRNA Networks Regulating Crop Milk Production in Pigeon (Columba livia)
}

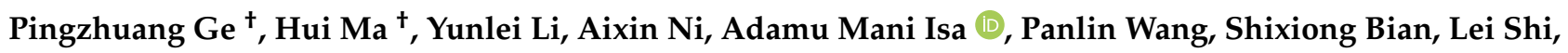 \\ Yunhe Zong, Yuanmei Wang, Linlin Jiang, Hailai Hagos, Jingwei Yuan, Yanyan Sun and Jilan Chen*
}

check for

updates

Citation: Ge, P.; Ma, H.; Li, Y.; Ni, A.; Isa, A.M.; Wang, P.; Bian, S.; Shi, L.;

Zong, Y.; Wang, Y.; et al. Identification of microRNA-Associated-ceRNA Networks Regulating Crop Milk Production in Pigeon (Columba livia). Genes 2021, 12, 39. https: / / doi.org/ 10.3390/genes12010039

Received: 13 November 2020 Accepted: 28 December 2020 Published: 30 December 2020

Publisher's Note: MDPI stays neutral with regard to jurisdictional clai$\mathrm{ms}$ in published maps and institutional affiliations.

Copyright: $\odot 2020$ by the authors. Licensee MDPI, Basel, Switzerland. This article is an open access article distributed under the terms and conditions of the Creative Commons Attribution (CC BY) license (https:// creativecommons.org/licenses/by/ $4.0 /)$.
Institute of Animal Sciences, Chinese Academy of Agricultural Sciences, Beijing 100193, China; 82101182352@caas.cn (P.G.); mahui@caas.cn (H.M.); liyunlei@caas.cn (Y.L.); $82101172347 @$ caas.cn (A.N.); 2018y90100036@caas.cn (A.M.I.); 82101179306@caas.cn (P.W.); $82101181193 @$ caas.cn (S.B.); 82101181189@caas.cn (L.S.); 82101185162@caas.cn (Y.Z.); 82101185166@caas.cn (Y.W.); 82101182353@caas.cn (L.J.); 2018y90100119@caas.cn (H.H.); yuanjingwei@caas.cn (J.Y.); sunyanyan@caas.cn (Y.S.)

* Correspondence: chenjilan@caas.cn; Tel.: +86-10-628-160-05

+ These authors contribute equally to this manuscript.

\begin{abstract}
Pigeon belongs to altrices. Squab cannot forage independently. Nutrition can only be obtained from crop milk secreted by male and female pigeon. miRNA could regulate many biological events. However, the roles of miRNA and ceRNA in regulating crop milk production are still unknown. In this study, we investigated the miRNAs expression profile of female pigeon crop, explored the potential key genes, and found the regulatory mechanisms of crop milk production. A total of 71 miRNAs were identified differentially expressed significantly. Meanwhile, miR-20b-5p, miR-146b-5p, miR-21-5p, and miR-26b-5p were found to be the key miRNAs regulating lactation. Target genes of these miRNAs participated mainly in cell development; protein and lipid synthesis; and ion signaling processes, such as cell-cell adhesion, epithelial cell morphogenesis, calcium signaling pathway, protein digestion, and absorption. In the ceRNA network, miR-193-5p was located in the central position, and miR-193-5p/CREBRF/LOC110355588, miR-460b-5p/GRHL2/MSTRG.132954, and miR-193-5p/PIK3CD/LOC110355588 regulatory axes were believed to affect lactation. Collectively, our findings enriched the miRNA expression profile of pigeon and provided novel insights into the microRNA-associated-ceRNA networks regulating crop milk production in pigeon.
\end{abstract}

Keywords: competing endogenous RNA; crop milk; lactation; pigeon

\section{Introduction}

Centuries ago, bird fanciers and naturalists had known that crops of parental pigeons could produce materials that nourished their springs [1]. Bernard (1859) first named it as crop milk and found that it consisted of clumps of epithelial cells shedding from the mucosal layer. As the only nutrition source of squab [2], crop milk has high nutritional value at the 1st, 2 nd and 3rd weeks after hatching [3-5]. The lipid content of crop milk consisted mainly of triglycerides, along with phospholipids, cholesterol, free fatty acids, cholesterol esters, and diglycerides [6]. Young pigeons fed with crop milk showed remarkable growth rates, reaching 8-, 18- and 22-fold of the hatching weight. Feeding with granules including crop milk could improve the growth of domestic chickens and weaning rats significantly [7-11]. The crop has considerable expandability, particularly in granivores. Comparing with other poultry, except for temporary storage of ingesta and softening food, pigeon crop is more specialized for its milk production ability [12].

There were few studies on the lactating process of pigeon crop, and prolactin was the most widely investigated. As reported, prolactin promotes mitosis and early signal transduction, and growth of special epithelial cells lining the crop of pigeons could regulate the synthesis of crop milk proteins by activating the IRS1/Akt/TOR signaling pathway [13], which promotes the formation of crop milk [1,4]. Research on the molecular mechanism of 
pigeon crop lactation has mainly focused on the genes regulating synthesis and transport of proteins and fatty acids and their enriched pathways [14-16]. Gillespie has investigated the mRNA transcriptome of crop milk production and found that cornification-associated genes (including S100-A9, cornulin and A16-like) as well as $\beta$-keratin genes were upregulated in the lactating crop. Pathway enrichment revealed the up-regulated genes involved in the proliferation of melanocytes, the adherens junction and the wingless signal pathways [17]. However, the interplay between coding and non-coding RNAs regulating the lactation process in pigeon is still unknown.

Competing endogenous RNA (ceRNA) hypothesis was proposed by Leonardo Salmena asserted [18], which states a genome-wide regulatory network could be formed through the communication of mRNA, pseudogenes, IncRNAs, and circRNAs via miRNA response elements (MREs). Experimental ceRNAs involving mRNA, pseudogenes, lncRNA, and circRNA were later verified in vivo [19]. miRNAs, therefore, remain at the center of ceRNAs cross-talk. miRNAs are about 22 nucleotides long molecules that bind to partial complementary sequences on the target RNA transcript, known as MREs, leading to inhibition or repressing of target gene expression [20,21]. The expression profile of miRNA in mammary glands of mice, cows, pigs, and other mammals was very rich [22-25], and there is lots of evidence that miRNA can regulate mammary gland development [26] and milk composition synthesis [27]. However, the research on pigeon milk production has not been carried out yet. In this study, we focused on the changes of miRNA expression between lactating and non-lactating crops and further combined the lncRNA, circRNA and mRNA data [28] to explore the potential mechanism of miRNA-associated-ceRNAs regulating crop milk production in pigeon.

\section{Materials and Methods}

\subsection{Ethics Statement}

All experiments using animals were approved by the animal care and use committee of the Institute of Animal Science, Chinese Academy of Agricultural Sciences (IAS 2018-3). All procedures were conducted in accordance with institutional animal ethics guidelines set by the Ministry of Agriculture of the People's Republic of China.

\subsection{Experimental Animals and Sample Collection}

Ten healthy female White King pigeons were obtained from a pigeon breeding farm in Beijing, including five lactating (at lactating day 3 ) and five non-lactating birds. Pigeons were slaughtered by $\mathrm{CO}_{2}$ asphyxiation. The crop tissues were removed aseptically. Then they were cut into small pieces of $1 \mathrm{~cm}$ thickness and frozen in liquid nitrogen immediately.

\subsection{RNA Isolation and Quality Assessment}

The total RNA was extracted from samples of the crop tissue using TRIzol reagent (Invitrogen, Carlsbad, CA, USA) according to the manufacturer's protocol. The RNA purity was checked using a Nanodrop Spectrophotometer (Model kaiaoK5500 ${ }^{\circledR}$, Beijing, China). The integrity and concentration of the RNA were measured by the RNA Nano 6000 Assay Kit of the Bioanalyzer 2100 system (Agilent Technologies, San Diego, CA, USA).

\section{4. miRNA Library Construction and Sequencing}

Total RNA was separated by 15\% agarose gels to extract the small RNA (18-30 nt). After being precipitated by ethanol and centrifugal enrichment of small RNA sample, the library was prepared according to the method and process of Small RNA Sample Preparation Kit (Illumina, RS-200-0048, San Diego, CA, USA). The main contents are as follows: 1 . Connecting the $3^{\prime}$ adaptor to the separated small RNA. 2. Connecting the $5^{\prime}$ adaptor to the separated small RNA. 3. Quantitative real-time PCR. 4. Recycling strips of $145-160$ bp (22-30 nt RNA). After library construction, miRNA sequencing was performed by using the Illumina HiSeq ${ }^{\mathrm{TM}} 2500$ platform (Annoroad, Beijing, China) and generating 50 bp single-end reads. 


\subsection{Quality Control, Mapping and Acquisition of Sequencing Data}

Raw Data were processed with perl scripts to ensure the quality of data used in the following analysis. The adopted filter criteria are: 1 . Reads without $3^{\prime}$ adapter were filtered out. 2. Reads with the number of bases whose phred quality value was no more than 19 accounting for more than $15 \%$ were regarded as low-quality reads and were filtered out. 3. Reads with the number of $\mathrm{N}$ bases accounting for more than $10 \%$ were filtered out.

The reference genome (https:/ / ftp.ncbi.nlm.nih.gov/genomes/all/GCF/000/337/ 935/GCF_000337935.1_Cliv_1.0/GCF_000337935.1_Cliv_1.0_genomic.fna.gz) and annotation file (https:/ / ftp.ncbi.nlm.nih.gov/genomes/all/GCF/000/337/935/GCF_00033793 5.1_Cliv_1.0/GCF_000337935.1_Cliv_1.0_genomic.gff.gz) were downloaded from NCBI database. The previous mRNAs and lncRNAs sequencing data [28], which can be downloaded from China National Genomics Data Center (https:/ /bigd.big.ac.cn/search/?dbId= gsa\&q=CRA001977), were reanalyzed. These sequences were generated using libraries constructed from the same RNA used in the current study. Clean data of mRNA and lncRNA were mapped to the reference genome using HISAT2 (version 2.0.5, parametersRNA-strandness RF-dta-t-p 4, https:/ / daehwankimlab.github.io/hisat2/) [29]. StringTie (version 1.3.2d, parameters -G ref.gtf-rf -1, http:/ / ccb.jhu.edu/software/stringtie/) [30] was run to build consensus sets of transcripts. As for miRNA reads, Bowtie (version 1.1.2, parameters-v0-p4-best, http:/ / bowtie-bio.sourceforge.net/index.shtml) [31] was used to build the reference genome index and then mapthe clean reads to the pigeon genome.

\subsection{Identification of miRNA, $\operatorname{lnc} R N A$ and $m R N A$}

Reads were mapped to mature miRNA and hairping, which were recorded in miRBase (release 21) [32], to identify known miRNA. Other clean reads were compared with ncRNA sequences in Rfam (version 13.0, https://rfam.org/) [33] to annotate rRNA tRNA snRNA snoRNA and other ncRNAs. After excluding the reads mapped to known miRNA, ncRNA, repeat region, and mRNA region, the remaining reads were used to predict novel miRNA by miRDeep2 (version 2.0.0.8, https: / / www.osc.edu/book/export/html/4389) [34].

The assembled transcripts were further subjected to a stringent filtering progress to obtain the candidate lncRNAs. First, we removed the transcripts with one exon and with lengths of less than $200 \mathrm{bp}$. Next, we calculated the reads' coverage of transcripts using String Tie [30] and removed transcripts with a reads' coverage of less than three. Subsequently, we eliminated known genes, pre-micro RNA and other non-coding RNAs (rRNA, tRNA, snoRNA and snRNA) using Cuffcompare.

\subsection{Differentially Expressed Analysis of RNAs}

Cuffdiff (v2.1.1) was used to calculate fragments per kilo-base of exon per million mapped fragments (FPKM) values for the lncRNAs and mRNAs, and TPM (transcripts per million) scores for the miRNAs.TPM normalization formula is as follows: $\mathrm{TPM}=$ (specific miRNA reads $\times 1,000,000) /$ total miRNA mapped reads. Genes with $\mathrm{P}$-adj $\leq 0.05$ and $\mid \log$ 2(Fold change) $\mid \geq 1$ were considered as differentially expressed. DESeq (version 1.16.0, parameters-fc 2-p 0.05-q 0.05, http:/ / www.bioconductor.org/packages / release/bioc/html/DESeq.html) [35] was used for different expression analysis.

\section{8. miRNA Target Prediction}

The miRNA targets prediction for the three other ceRNAs (mRNA, lncRNA and circRNA) was achieved using PITA (version 6, parameters-gxp-1 6-8, http:/ / genie.weizmann. ac.il/pubs/mir07/mir07data.html) [36], miRanda (version 3.3a, parameters-sc 180-en 20-strict, http://www.microrna.org/) [37] and Target Scan (version 3.1, http://www. targetscan.org/vert_72/) [38], and at least two software intersections.

\subsection{Functional Enrichment}

The differentially expressed target genes of the differentially expressed miRNAs were subjected to Gene Ontology (GO, releases/2019-05-09, http:/ / geneontology.org/) 
enrichment using hypergeometric test. Similarly, enrichment of Kyoto encyclopedia of genes and genomes (KEGG, releases/2019-05-01, http://www.kegg.jp/) of the target genes was achieved by hypergeometric test. GO and KEGG terms with $p \leq 0.05$ were considered to be significantly enriched.

\subsection{Protein-Protein Interaction Analyze}

To get insight into the potential relationships of mRNAs, differentially expressed between lactating and non-lactating pigeon crops, PPI network was constructed using STRING (version 11.0, https://string-db.org/cgi/input.pl) and visualized in the cytoscape (version 3.6.1).

\subsection{Construction of ceRNA Network}

The ceRNA network was visualized using cytoscape software. The topological features of this ceRNA network were calculated by a built-in network analyzer tool in cytoscape software.

\subsection{Quantitative Real-Time PCR}

The RNA samples were reverse transcribed into cDNA using the miRcute plus miRNA first-strand cDNA Kit (TIANGEN, Beijing, China) following the manufacturers instructions. The concentration of the RNA samples was adjusted to $200 \mathrm{ng} / \mu \mathrm{L}$ by adding RNase free $\mathrm{ddH}_{2} \mathrm{O}$. The first step of the reverse transcription was conducted at $42{ }^{\circ} \mathrm{C}$ for $60 \mathrm{~min}$. It contained $5 \mu \mathrm{L}$ RNA samples, $10 \mu \mathrm{L} 2 \times$ miRNA RT reaction buffer, $2 \mu \mathrm{L}$ miRNA RT enzyme mix, and $3 \mu \mathrm{L}$ RNase free $\mathrm{dH}_{2} \mathrm{O}$. The second step was conducted at $95{ }^{\circ} \mathrm{C}$ for 3 min. qRT-PCR was performed using the miRcute plus miRNA qPCR Kit (TIANGEN, China) and the ABI Quant Studio 7 Flex Real-Time Detection System (Life Technologies Holdings Pte Ltd., USA). Each $10 \mu \mathrm{L}$ qRT-PCR mixture contained $5 \mu \mathrm{L} 2 \times$ miRcute plus miRNA premix (SYBR\&ROX), $0.2 \mu \mathrm{L}$ reverse primer $(10 \mu \mathrm{m}), 0.2 \mu \mathrm{L}$ forward primer, $1 \mu \mathrm{L}$ cDNA (100 ng), and $3.6 \mu \mathrm{L}$ RNase free $\mathrm{ddH}_{2} \mathrm{O}$. After an initial denaturing at $95{ }^{\circ} \mathrm{C}$ for $15 \mathrm{~min}$, there were 40 cycles of amplification $\left(94^{\circ} \mathrm{C}\right.$ for $20 \mathrm{~s}$ and $60^{\circ} \mathrm{C}$ for $\left.34 \mathrm{~s}\right)$, followed by a thermal denaturing $\left(95^{\circ} \mathrm{C}\right.$ for $15 \mathrm{~s}, 60^{\circ} \mathrm{C}$ for $60 \mathrm{~s}$, and $95^{\circ} \mathrm{C}$ for $15 \mathrm{~s}$ ) to generate melting curves. The miRNA primer design software was provided by Vazyme Biotech Co., Ltd. Nanjing, China.

The RNA samples were reverse transcribed into cDNA using the PrimeScript RT Reagent Kit (TaKaRa, Dalian, China) following the manufacturer's instructions. The concentration of the RNA samples was adjusted to $200 \mathrm{ng} / \mu \mathrm{L}$ by adding RNase free $\mathrm{ddH}_{2} \mathrm{O}$. The first step of the reverse transcription was conducted at $42{ }^{\circ} \mathrm{C}$ for $2 \mathrm{~min}$. It contained $5 \mu \mathrm{L}$ RNA samples, $1 \mu \mathrm{L}$ gDNA Eraser, $2 \mu \mathrm{L} 5 \times$ gDNA Eraser Buffer, and $2 \mu \mathrm{L}$ RNase free $\mathrm{ddH}_{2} \mathrm{O}$. The second step was conducted at $37^{\circ} \mathrm{C}$ for $15 \mathrm{~min}$, then at $85^{\circ} \mathrm{C}$ for 5s. It contained $10 \mu \mathrm{L}$ last step reaction solution, $1 \mu \mathrm{L}$ PrimeScript RT Enzyme Mix, $4 \mu \mathrm{L}$ $5 \times$ PrimeScript Buffer, $1 \mu \mathrm{L}$ RT Primer Mix, and $4 \mu \mathrm{L}$ RNase free $\mathrm{ddH}_{2} \mathrm{O}$. A qRT-PCR was performed using the PrimeScript One Step RT-PCR Kit (TaKaRa, Dalian, China) and the ABI Quant Studio 7 Flex Real-Time Detection System (Life Technologies Holdings Pte Ltd., Carlsbad, USA). Each $10 \mu \mathrm{L}$ qRT-PCR mixture contained $5 \mu \mathrm{L}$ SYBR Premix Ex TaqTM II, $0.5 \mu \mathrm{L}(10 \mathrm{pM})$, and in each primer there was $0.2 \mu \mathrm{L}$ ROX Reference Dye II $(50 \times), 1.5 \mu \mathrm{L}$ cDNA (100 ng) and $2.3 \mu \mathrm{L}$ RNase free $\mathrm{ddH}_{2} \mathrm{O}$. After an initial denaturing at $95{ }^{\circ} \mathrm{C}$ for $3 \mathrm{~min}$, there were $40 \mathrm{cycles}$ of amplification $\left(95^{\circ} \mathrm{C}\right.$ for $30 \mathrm{~s}$ and $60^{\circ} \mathrm{C}$ for $\left.34 \mathrm{~s}\right)$, followed by a thermal denaturing $\left(95^{\circ} \mathrm{C}\right.$ for $15 \mathrm{~s}, 60^{\circ} \mathrm{C}$ for $60 \mathrm{~s}$, and $95^{\circ} \mathrm{C}$ for $15 \mathrm{~s}$ ) to generate melting curves. The primers of the genes were designed by the Primer Premier 5 .

The primers in this study were summarized in Table S1. All mRNA expression data were normalized to hypoxanthine phosphoribosyltransferase 1 (HPRT1). All miRNA expression data were normalized to U6. The relative expression of the genes was calculated using the $2^{-\Delta \Delta \mathrm{Ct}}$ method. 


\subsection{Data Accessibility}

The sequencing data have been submitted to the SRA database (accession number: PRJNA612642). SRA records could be accessed via the following link (https://www.ncbi. nlm.nih.gov/sra/PRJNA612642).

\section{Results}

\subsection{Identification of Pigeon Small RNAs}

As reported in Ma et al., the clean reads rate in individual samples was above $88 \%$, and the clean Q30 bases rate was above $90 \%$ after data filtering [28]. For mapped reads, small RNAs, a total of $42.18 \%, 46.76 \%, 49.43 \%, 46.29 \%, 50.17 \%, 57.37 \%, 54.57 \%, 49.61 \%$, $50.83 \%$, and $47.74 \%$ reads from $\mathrm{C} 1, \mathrm{C} 2, \mathrm{C} 3, \mathrm{C} 4, \mathrm{C} 5, \mathrm{~T} 1, \mathrm{~T} 2, \mathrm{~T} 3, \mathrm{~T} 4$, and $\mathrm{T} 5$ were mapped to the pigeon reference genome (Table 1, Figure 1a), respectively. Known miRNA, rRNA, tRNA, snRNA, snoRNA, and novel miRNAs were identified after annotating for small RNAs. The number of known miRNAs accounted for more than $24 \%$ in all annotated small RNAs (Supplementary Table S2). In order of scale, miRNA $>$ tRNA $>$ rRNA $>$ snoRNA in all the libraries sequenced. Others were less than $1 \%$.

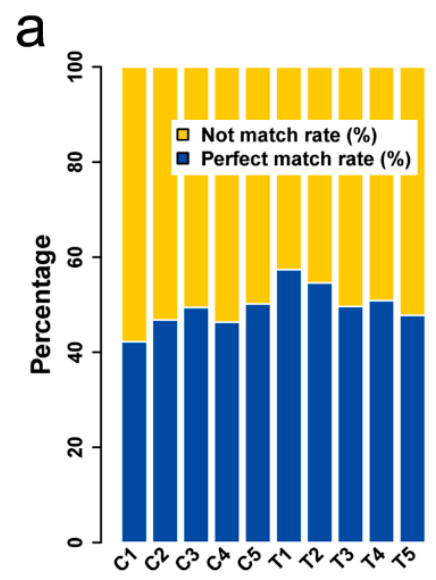

d

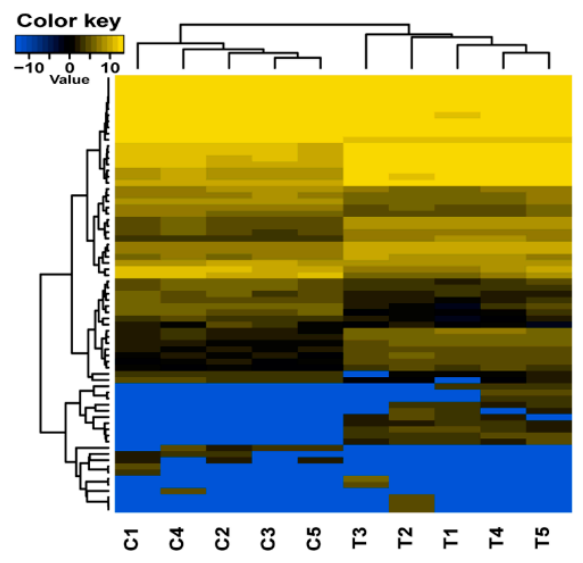

C

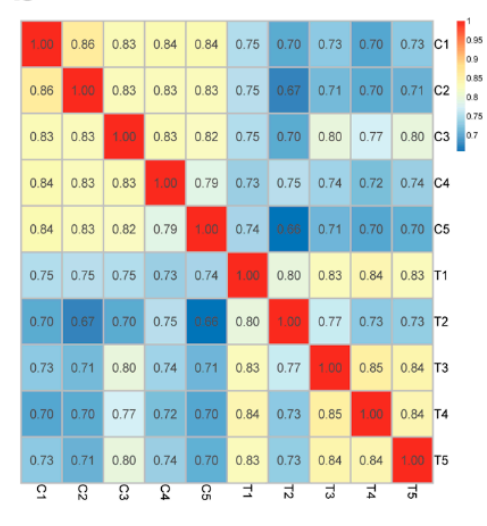

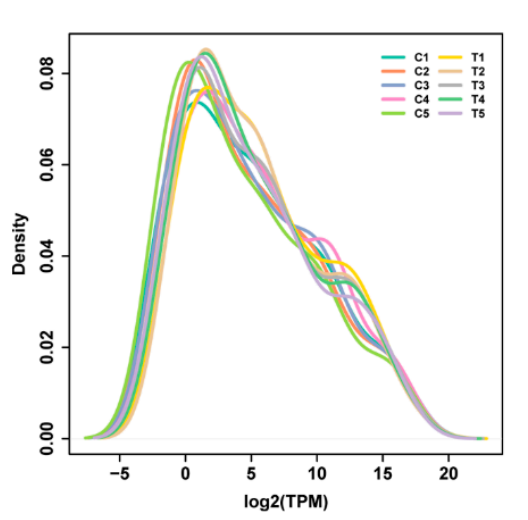

e

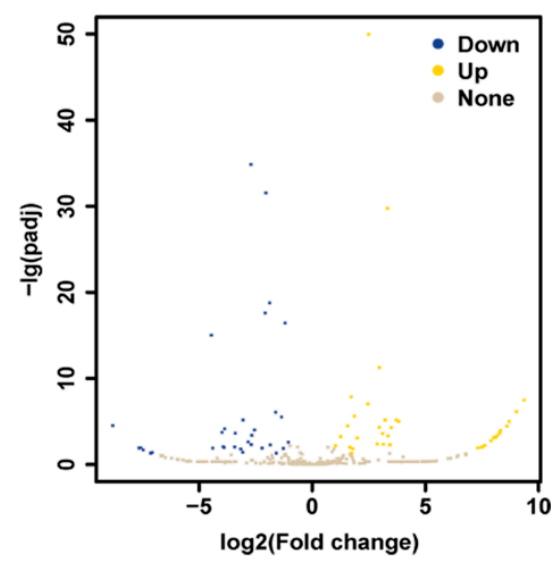

Figure 1. (a) Proportion of clean reads aligned to the pigeon reference genome. The abscissa represents the sample; the ordinate represents the percentage. (b) A Pearson correlation coefficients graph of individuals based on the TPM value. (c) Expression quantity distribution density diagram. (d) Heat map of differentially expressed miRNAs. (e) Volcano map of miRNA expression levels. Gray dots, yellow dots and blue dots represent miRNAs with no significant differences, up-regulated miRNAs and down-regulated miRNAs respectively. 
Table 1. Basic and mapping data of small RNA sequencing.

\begin{tabular}{ccccc}
\hline Sample & Total Reads & Match Reads & Match Rate, \% & Not Match Rate, \% \\
\hline C1 & $23,186,308$ & $9,780,560$ & 42.18 & 57.82 \\
C2 & $24,761,407$ & $11,578,750$ & 46.76 & 53.24 \\
C3 & $21,598,417$ & $10,675,774$ & 49.43 & 50.57 \\
C4 & $20,696,077$ & $9,580,916$ & 46.29 & 53.71 \\
C5 & $25,248,936$ & $12,668,115$ & 50.17 & 49.83 \\
T1 & $21,729,292$ & $12,465,242$ & 57.37 & 42.63 \\
T2 & $21,760,177$ & $11,875,079$ & 54.57 & 45.43 \\
T3 & $30,614,359$ & $15,187,405$ & 49.61 & 50.39 \\
T4 & $32,883,572$ & $16,714,329$ & 50.83 & 49.17 \\
T5 & $31,975,781$ & $15,266,339$ & 47.74 & 52.26 \\
\hline
\end{tabular}

A total of 386 miRNAs (188 known miRNAs, 198 novel miRNAs) was found to be expressed in the crop of lactating and non-lactating pigeons (Supplementary Tables S3 and S4). A good correlation among individuals in the stage was observed in the miRNA cluster map and density distribution map (Supplementary Table S4, Figure 1b,c). A total of 50 known miRNAs and 21 novel miRNAs were differentially expressed (Supplementary Table S5, Figure 1d,e). Top 10 differential expressed miRNAs were shown in Table 2, including four up-regulated and six down-regulated ones.

Table 2. Top 10 differentially expression miRNAs.

\begin{tabular}{cccc}
\hline Name & Log $_{2}($ FC & $p$-Value & Label \\
\hline cli-miR-7a-5p & 3.32 & $1.85 \times 10^{-32}$ & up \\
cli-miR-20b-5p & 2.97 & $1.29 \times 10^{-13}$ & up \\
cli-miR-21-5p & 2.49 & $2.86 \times 10^{-53}$ & up \\
cli-miR-146b-5p & 1.72 & $3.66 \times 10^{-10}$ & up \\
cli-miR-26-5p & -1.20 & $6.57 \times 10^{-19}$ & down \\
cli-miR-99-5p & -1.88 & $2.08 \times 10^{-21}$ & down \\
cli-miR-10a-5p & -2.05 & $2.14 \times 10^{-34}$ & down \\
cli-miR-100-5p & -2.08 & $3.72 \times 10^{-20}$ & down \\
cli-miR-125-5p & -2.71 & $7.37 \times 10^{-38}$ & down \\
cli-miR-145-5p & -4.45 & $2.01 \times 10^{-17}$ & down \\
\hline
\end{tabular}

\section{2. miRNA Target Prediction and Analyze}

mRNAs and lncRNAs targets of the differentially expressed miRNA were predicted using miRanda, PITA and Target scan databases. We identified 705 pairs of miRNA-mRNA (including 39 known miRNAs, 17 novel miRNAs and 620 mRNAs), 172 pairs of miRNAlncRNA (including 28 known miRNAs, 12 novel miRNAs and 75 lncRNAs) and a pair of miRNA-circRNA. The characteristic descriptions of RNAs are shown in Figure 2.

a

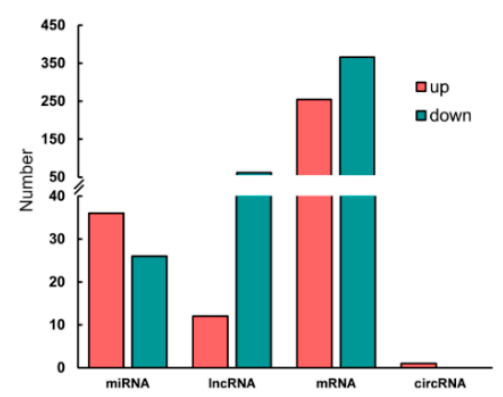

b

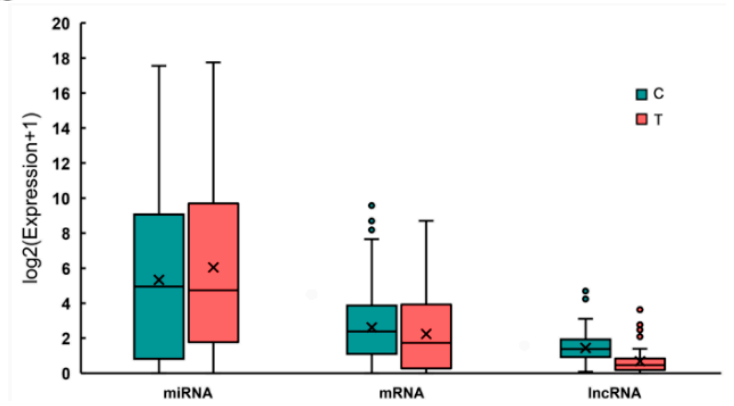

Figure 2. (a) The number of up/down regulation of different type RNAs in pigeon crop. (b) Cumulative distribution of RNA expression. 
GO and KEGG pathway analyses of the target mRNAs of differentially expressed miRNA were performed. The target genes were enriched in $52 \mathrm{GO}$ biological process items and 14 KEGG pathways (Supplementary Tables S6 and S7), including development process, cell-cell adhesion, epithelial cell morphogenesis, calcium signaling pathway, protein digestion and absorption, and glycosaminoglycan biosynthesis—of keratan sulfate (Figure 3).

a

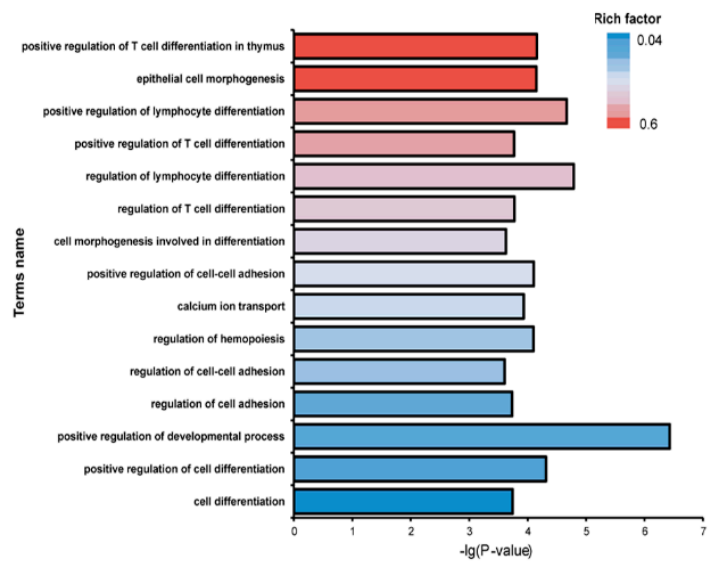

b

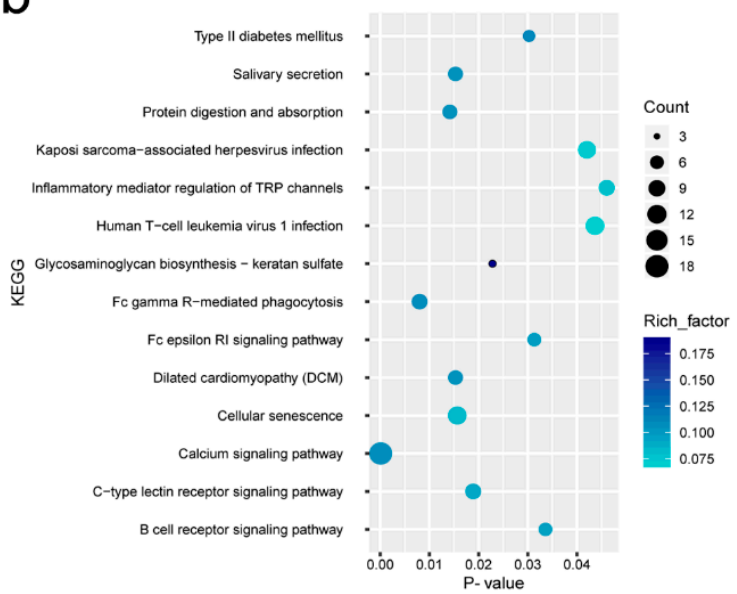

Figure 3. (a) Enriched biological process for target genes of differentially expressed miRNAs genes between lactating and non-lactating pigeon crop. (b) KEGG pathways enriched in target genes of the differentially expressed miRNAs between lactating and non-lactating pigeon crops.

\subsection{PPI Network}

The 620 target mRNAs of the differentially expressed miRNAs were submitted to string online tool where PPI network was constructed. Over $45 \%$ of the target mRNAs were nodes in the complex PPI network (Figure 4, Supplementary Table S8). Glutamyl-prolyl tRNA synthetase (EPRS), XP 005509099.1, sterol regulatory element-binding protein 1 (SREBF1), acetyl-CoA carboxylase $\alpha$ (ACACA), and protein phosphatase type $1 \alpha$ (PPP1CA) were identified as the most highly connected nodes in the network.

\section{4. miRNA-mRNA-lncRNA/circRNA Interaction Network}

The interaction information of miRNA-mRNA, miRNA-IncRNA and miRNA-circRNA were predicted by PITA, miRanda and target scan. Based on these data, we constructed miRNA-mRNA-lncRNA/circRNA ceRNA regulatory networks and visualized them via cytoscape software. LncRNAs, circRNAs and mRNAs were connected by the same target miRNAs, and 1619 regulatory triplets (1024 pairs known miRNA-mRNA-lncRNA, 575 pairs novel miRNA-mRNA-lncRNA and 20 pairs miRNA-mRNA-circRNA) were obtained (Figure $5 \mathrm{a}-\mathrm{c}$ ). The topological features of ceRNA network were assessed by a built-in network analyzer tool in cytoscape software, including betweenness, network degree, and closeness centrality.

Statistics of four types of RNA degree value, betweenness centrality and closeness centrality in the network, retain higher degree value RNAs (Table 3) as the hub of ceRNA network. miR-193-5p, miR-92-2-5p, miR-7b-5p, and CREB3 regulatory factor (CREBRF) were at the core of the network, with the most lncRNAs and mRNAs associated with them. cli-let-7c-5p was the only miRNA connected to the lone target circRNA (circ_0003020). 


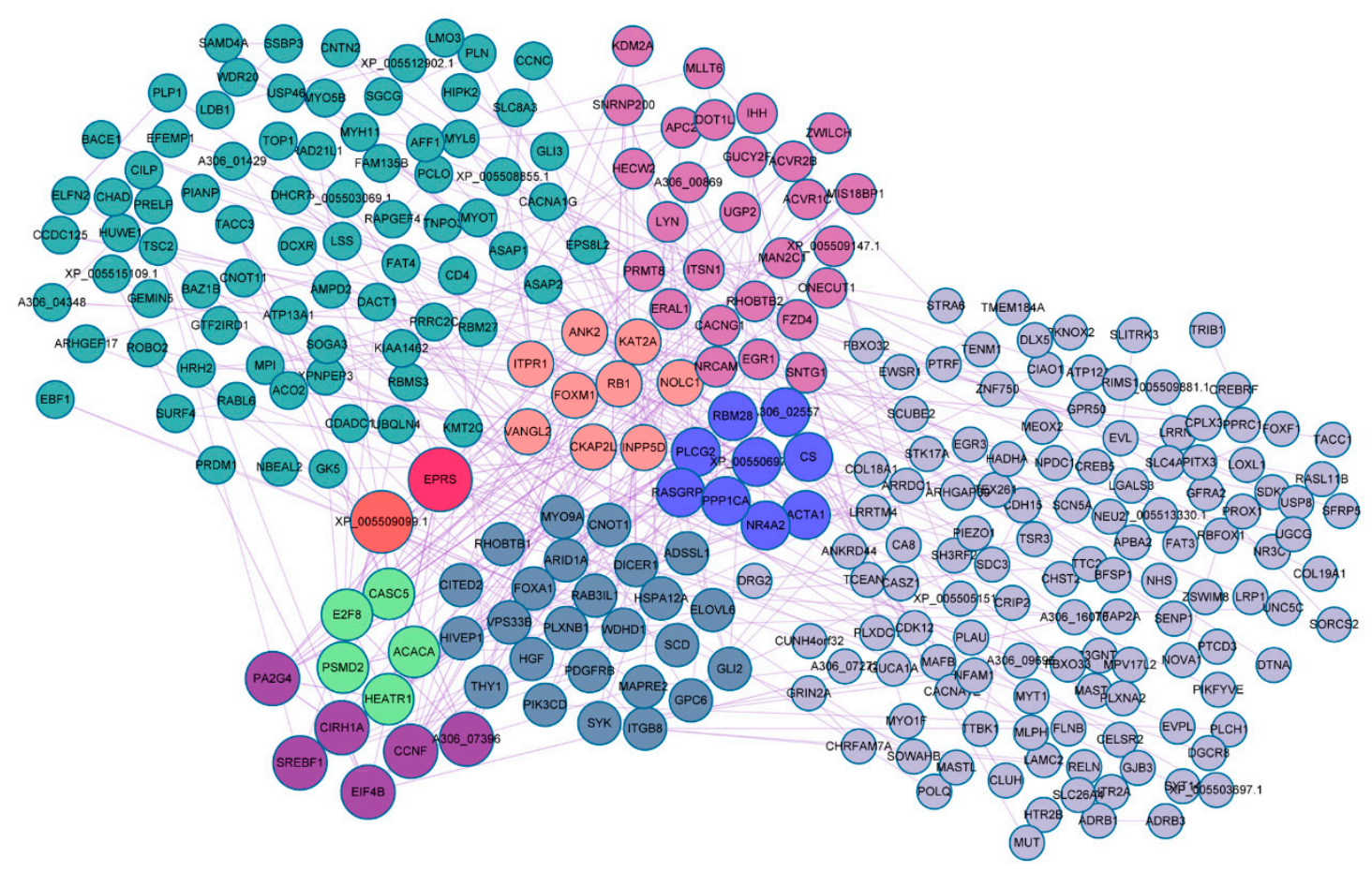

Figure 4. Summary of protein-protein interaction network of target genes of the differentially expressed miRNAs between lactating and non-lactating pigeon crops. Different colors represent modules, and size of the node represents connectedness of the node.

Table 3. Hub RNAs of ceRNA network.

\begin{tabular}{ccccc}
\hline Name & Betweenness Centrality & Closeness Centrality & Degree & Class \\
\hline cli-miR-193-5p & 0.99 & 0.70 & 389 & miRNA \\
cli-miR-92-2-5p & 0.18 & 0.33 & 53 & miRNA \\
cli-miR-7b-5p & 0.93 & 0.77 & 14 & miRNA \\
cli-miR-214-5p & 0.05 & 0.30 & 13 & miRNA \\
cli-miR-106-5p & 0.06 & 0.30 & 10 & miRNA \\
Novel_189 & 0.09 & 0.58 & 22 & miRNA \\
Novel_188 & 0.09 & 0.58 & 22 & miRNA \\
Novel_187 & 0.09 & 0.58 & 22 & miRNA \\
cli-let-7c-5p & 1.00 & 1.00 & 21 & miRNA \\
TTC28 & 0.01 & 0.23 & 3 & mRNA \\
CREBRF & 0.03 & 0.42 & 2 & mRNA \\
SCML4 & 0.03 & 0.42 & 2 & mRNA \\
RAPGEF4 & 0.00 & 0.41 & 2 & mRNA \\
STRA6 & 0.02 & 0.45 & 2 & mRNA \\
LOC110358245 & 0.13 & 0.60 & 8 & mRNA \\
PLN & 0.02 & 0.50 & 7 & mRNA \\
UGCG & 0.02 & 0.50 & 7 & mRNA \\
DOT1L & 0.00 & 0.51 & 1 & mRNA \\
MSTRG.71575 & 0.01 & 0.23 & 3 & lncRNA \\
MSTRG.151245 & 0.01 & 0.23 & 3 & lncRNA \\
MSTRG.2421 & 0.01 & 0.23 & 3 & lncRNA \\
LOC110360772 & 0.00 & 0.16 & 2 & lncRNA \\
MSTRG.81107 & 0.14 & 0.53 & 2 & lncRNA \\
MSTRG.1547 & 0.14 & 0.53 & 2 & lncRNA \\
circ_0003020 & 0.00 & 0.51 & 1 & circRNA \\
\hline
\end{tabular}




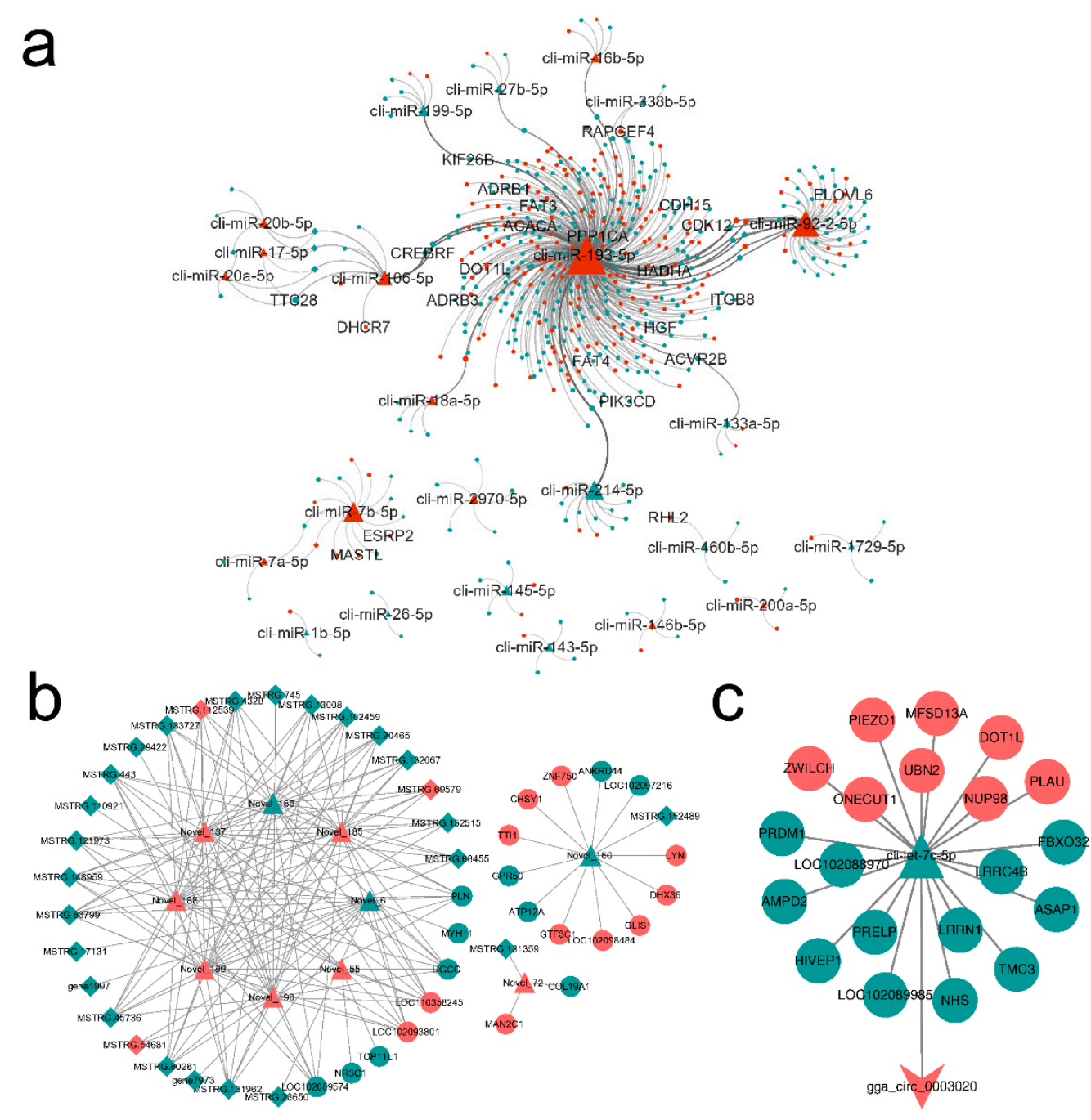

Figure 5. ceRNA network for target RNA molecules of the differentially expressed miRNAs between lactating and nonlactating pigeon crops. Triangular, ellipse, diamond, and V nodes represent miRNA, mRNA, IncRNA and circRNA respectively. Red represents up-regulation and green represents down-regulation. The ceRNAs were connected by edges. (a) known miRNA-mRNA-lncRNA network. (b) Novel miRNA-mRNA-lncRNA network. (c) miRNA-mRNA-circRNA network.

\subsection{Functional Annotation of the mRNAs in ceRNA Network}

Functional enrichment analysis of mRNA targets of differentially expressed miRNAs was conducted to explore the function of mRNA in ceRNA network. These mRNAs were significantly enriched in 25 GO terms, including cell motility, cell migration, and calcium ion binding (Figure 6a). Only calcium signaling pathway and focal adhesion were significantly enriched in the KEGG pathway. The DEGs in the pathway are shown in the heat maps (Figure $6 \mathrm{~b}, \mathrm{c}$ ).

\subsection{Construct Fatty Acid Biosynthesis Pathway Function Network}

Lipids were extremely important nutrients in crop milk, and we identified many genes that played an important role in the extension, synthesis and metabolism of fatty acids. So, we constructed a metabolic sub-network related to fatty acid biosynthesis (Figure 7). Metabolic networks were involved in insulin, PI3K-Akt, ECM-receptor interaction, GAP junction, fatty acid biosynthesis and extension, $\mathrm{FoxO}$, and cell cycle signaling pathways. Purple ovals represent proteins involved in pathways. Pink ovals represent the differentially expressed genes identified in this study. The nine genes (hepatocyte growth factor 
(HGF), laminin subunit $\gamma 2$ (LAMC2), integrin subunit $\beta 8$ (ITGB8), platelet derived growth factor receptor $\beta$ (PDGFRB), phosphatidylinositol-4,5-bisphosphate 3-kinase catalytic subunit delta (PIK3CD), adrenoceptor $\beta 1$ (ADRB1), ACACA, ELOVL fatty acid elongase 6 (ELOVL6), hydroxyacyl-CoA dehydrogenase/3-ketoacyl-CoA thiolase/enoyl-CoA hydratase (trifunctional protein), and $\alpha$ subunit $(H A D H A)$ were involved in the ceRNA network.

As shown in Figure 7, these differentially expressed genes were involved in various steps of fatty acid elongation and synthesis. In particular, $A C A C A$ and elongation of very long-chain fatty acid proteins ( $E L O V L)$ have also been identified as differentially expressed. The synthesized products were also associated with signal pathways such as cutin, suberin and wax biosynthesis and fatty acid degradation.

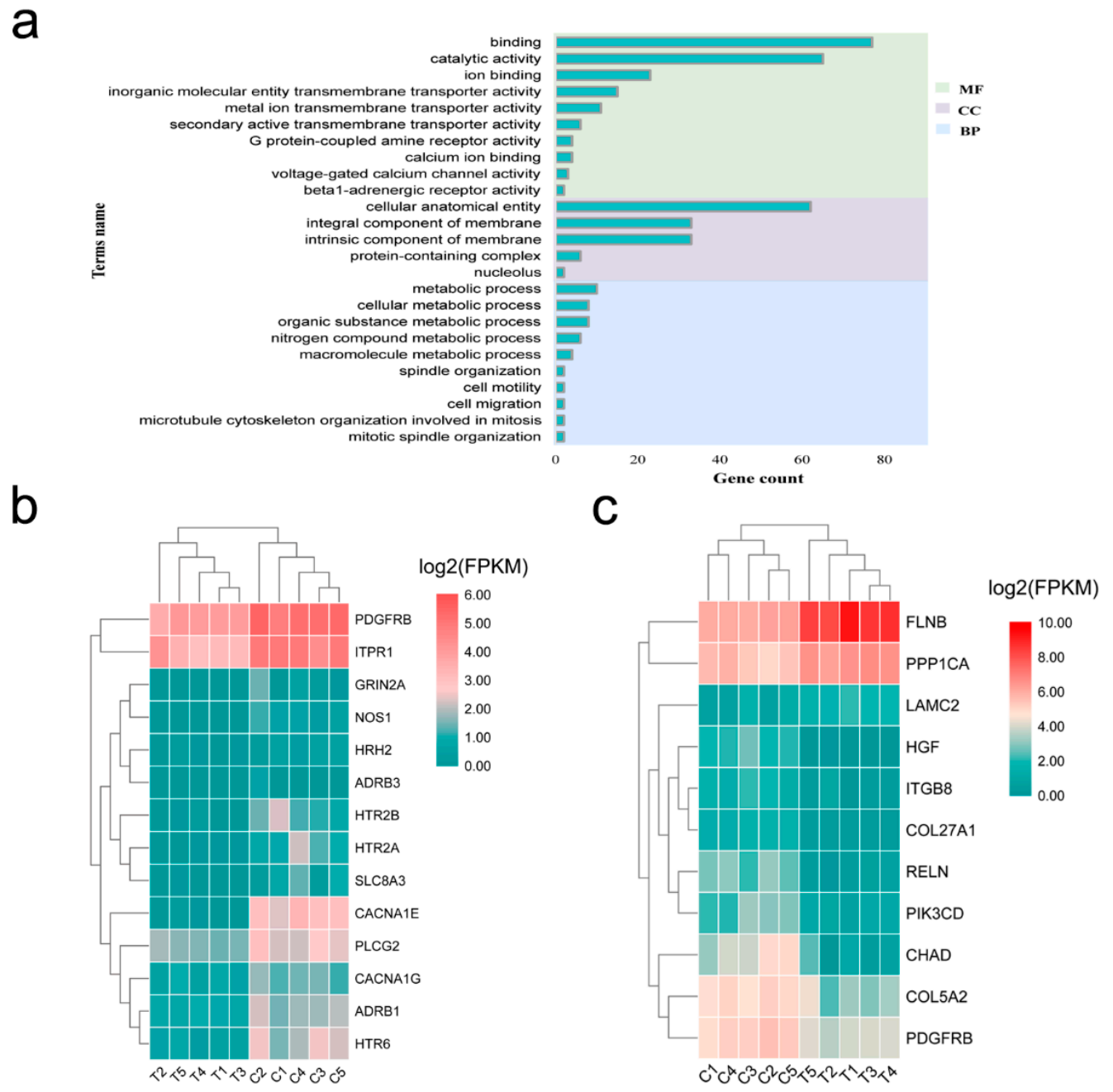

Figure 6. Functional enrichment analysis of the mRNA targets of the differentially expressed miRNAs between the lactating and non-lactating pigeon crops. (a) GO analysis; (b) Heatmap displaying the lactation-related genes identified in calcium signaling pathway; (c) Heatmap displaying the lactation-related genes identified in focal adhesion pathway. C, non-lactating group; T, lactating group. 


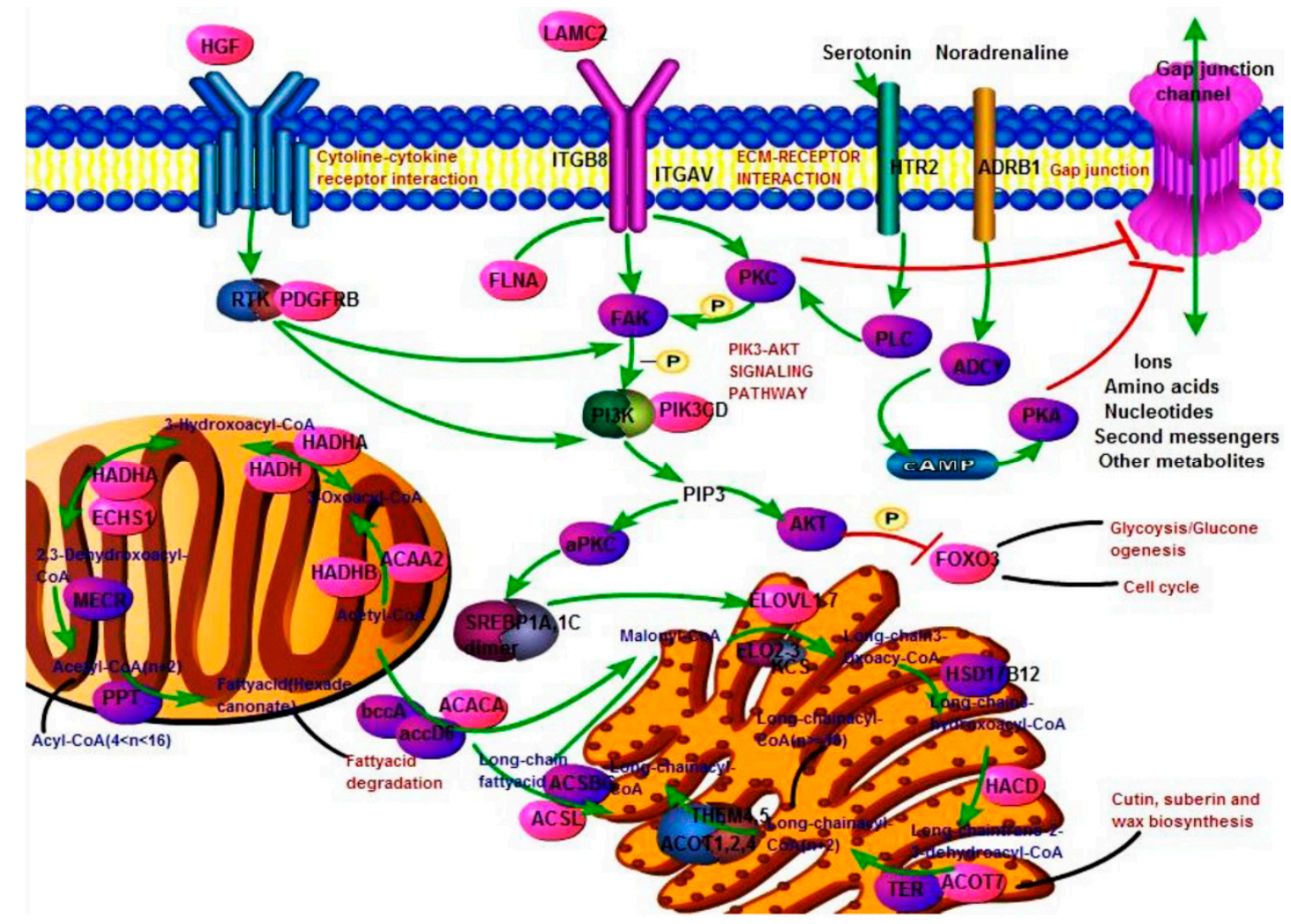

Figure 7. Fatty acid biosynthesis function network. The red molecule and other color molecule respectively represent DEGs and unidentified genes. The green line and the black line represent direct connection and indirect connection. The blue and red letters represent chemical molecules and pathways.

\subsection{The Exploration of ceRNA Regulates Axes}

The key regulation axis of ceRNA regulating the crop milk production was screened by integrating the results of targeted relationship and functional regulation network. The results are shown in Table 4. miR-193-5p and many associated with pigeon milk production key genes were predicted as a target relationship. MSTRG.65211 and LOC110355588 might be in competition with miR-193-5p to regulate gene expression.

Table 4. Key ceRNA regulation axis.

\begin{tabular}{cccccc}
\hline miRNA & Label & mRNA & Label & lncRNA & Label \\
\hline cli-miR-193-5p & up & CREBRF & down & MSTRG.65211 & down \\
cli-miR-193-5p & up & ADRB1 & down & MSTRG.65211 & down \\
cli-miR-193-5p & up & IHH & down & MSTRG.65211 & down \\
cli-miR-193-5p & up & ADRB3 & down & MSTRG.65211 & down \\
cli-miR-193-5p & up & CDH15 & down & MSTRG.65211 & down \\
cli-miR-193-5p & up & PIK3CD & down & MSTRG.65211 & down \\
cli-miR-193-5p & up & ITGB8 & down & MSTRG.65211 & down \\
cli-miR-193-5p & up & HGF & down & MSTRG.65211 & down \\
cli-miR-193-5p & up & PDGFRB & down & MSTRG.65211 & down \\
cli-miR-193-5p & up & CREBRF & down & LOC110355588 & down \\
cli-miR-193-5p & up & ADRB1 & down & LOC110355588 & down \\
cli-miR-193-5p & up & ADRB3 & down & LOC110355588 & down \\
cli-miR-193-5p & up & CDH15 & down & LOC110355588 & down \\
cli-miR-193-5p & up & PIK3CD & down & LOC110355588 & down \\
cli-miR-193-5p & up & ITGB8 & down & LOC110355588 & down \\
cli-miR-193-5p & up & HGF & down & LOC110355588 & down \\
\hline
\end{tabular}


Table 4. Cont.

\begin{tabular}{ccclll}
\hline miRNA & Label & mRNA & Label & \multicolumn{1}{c}{ lncRNA } & Label \\
\hline cli-miR-193-5p & up & PDGFRB & down & LOC110355588 & down \\
cli-miR-193-5p & up & IHH & down & LOC110355588 & down \\
cli-miR-106-5p & up & CREBRF & down & MSTRG.71575 & down \\
cli-miR-106-5p & up & CREBRF & down & MSTRG.2421 & down \\
cli-miR-106-5p & up & CREBRF & down & MSTRG.151245 & down \\
cli-miR-338b-5p & down & RAPGEF4 & up & MSTRG.20439 & down \\
cli-miR-460b-5p & down & GRHL2 & up & MSTRG.132954 & down \\
cli-let-7c-5p & down & DOT1L & up & circ-0003020 & down \\
\hline
\end{tabular}

\subsection{Validation of Differentially Expressed RNAs}

A total of seven miRNAs and seven mRNAs were chosen for qRT-PCR validation of the RNA sequencing results in lactating and non-lactating pigeon crop. $A C A C A, \mathrm{E}-$ cadherin (CDH1), ELOVL6, DOT1 like histone lysine methyltransferase (DOT1L), epithelial splicing regulatory protein 2 (ESRP2), and miR-200a-5p were identified to be upregulated in lactating crop compared to non-lactating, whereas tetratricopeptide repeat domain 28 (TTC28), PIK3CD, let-7c-5p, let-7a-5p, miR-26-5p, miR-10a-5p, miR-99-5, and miR-125-5p were downregulated (Figure 8). These results were consistent with the sequencing results. Therefore, differential expression of these mRNAs might be involved in the process of crop milk production.

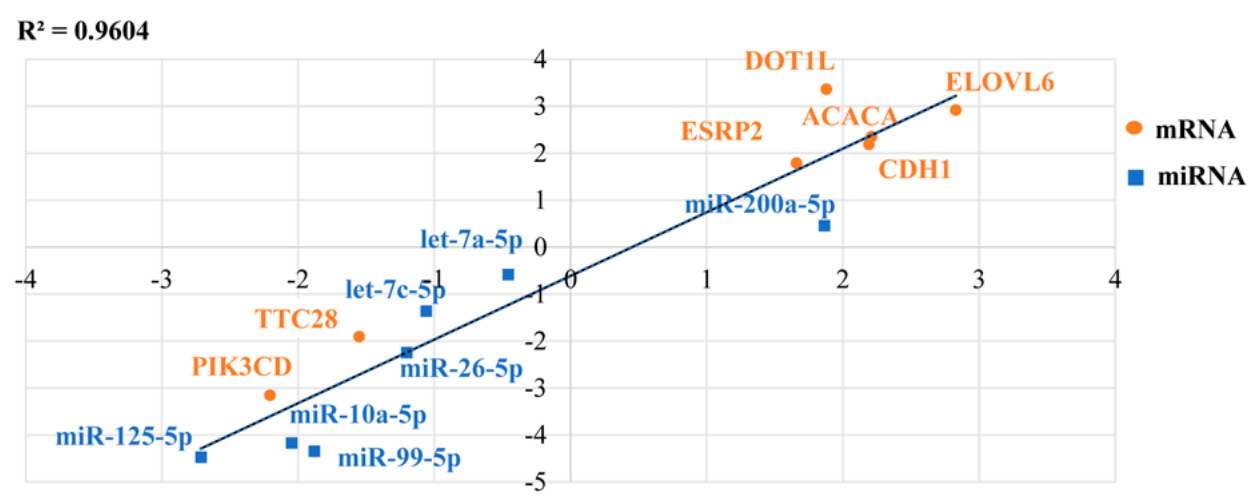

Figure 8. An illustration of the qRT-PCR confirmation for the RNA-seq. The correlations of the gene expression level of the 14 differentially expressed genes between lactating and non-lactating crops using RNA-Seq and a qRT-PCR. The X-axis and Y-axis show the $\log _{2}$ Fold change $(\mathrm{T} / \mathrm{C})$ measured by the RNA-seq and qRT-PCR, respectively. T represents lactating group and $C$ represents non-lactating group. The hypoxanthine phosphoribosyltransferase 1 (HPRT1) gene was used as a housekeeping internal control.

\section{Discussion}

Male and female pigeons have the ability to produce nutrients in their crop for the nourishment of their young. The production of the nutrient has been likened to lactation in mammals, and hence, it has been called crop milk [39]; meanwhile, the pigeon crop undergoes significant changes to the tissue structure during lactation [17]. miRNAs have demonstrated to play crucial functions in lipid metabolism, adipose tissue development and immune response [40-42]. In the present study, we found that over $40 \%$ of the small RNAs in pigeon crop were miRNAs; a total of 71 miRNAs were identified as significantly differentially expressed. We hypothesized that these differentially expressed miRNAs are involved in crop tissue morphological changes and pigeon milk synthesis. Histological studies showed that the layers of cells in the crop during lactation proliferated and that there were shed epithelial cells in the pigeon milk $[43,44]$. We noticed that many miRNAs involved in cell proliferation and migration have been identified, such as miR-20b-5p, 
which was proved to participate in the epithelial mesenchymal transition (EMT), migration and invasion process of prostate cancer [45]. MiR-146b-5p played a regulatory role in the proliferation and differentiation of human fibroblasts and chicken myoblasts $[46,47]$. MiR-21-5p is up-regulated in a variety of cancer cells such as non-small cell lung cancer, Hepatocellular carcinoma, melanoma, and colon adenocarcinoma cells, and has been shown to promote cell proliferation [48-51]. MiR-193-5p downregulation has significant angiogenic effect by inducing migration and proliferation in myocardial microvascular endothelial cells. Insulin-like growth factor 2 (IGF2) acted as a direct regulator to prevent this process from happening [52]. Gillespie suggested that the exfoliation of the crop epithelium due to inadequate blood supply leads to cellular keratinization [39], which may be an effect of miR-193-5p upregulation and inhibition of angiogenesis during lactation. Furthermore, Luo et al. found that miR-26b-5p serves as a direct negative regulator of TCF4 expression within human adipose-derived mesenchymal stem cell, leading to inactivation of the Wnt/ $\beta$-catenin pathway and thereby promoting the adipogenic differentiation of these cells in vitro [53]. This function is closely related to the characteristics of pigeon milk with high fat and nutrition. Based on the above evidence, we speculated that these miRNAs played an important role in the proliferation and exfoliation of the crop epithelial cells during the lactation period.

In order to further explore the functions of miRNAs, target gene prediction and functional enrichment analysis were performed. We identified 620 differentially expressed target genes and 75 differentially expressed target lncRNAs for differentially expressed miRNAs. By performing functional enrichment analysis of these genes, it was found that GO categories and pathways for DEGs such as development process, cell-cell adhesion, epithelial cell morphogenesis, calcium signaling pathway, protein digestion and absorption, and glycosaminoglycan biosynthesis of keratan sulfate signaling pathways were enriched between lactation and non-lactation periods. PPI analysis revealed EPRS, SREBF1 and $A C A C A$ closely associated with adipogenesis, degeneration, and lipid accumulation $[54,55]$. These results suggested that genes regulating substance synthesis remained active to support the synthesis of a large number of milk compositions in lactation.

Further, we found several GO terms related to cell adhesion and calcium signaling pathway. Classical cadherins are the key molecules that control cell-cell adhesion and are essential regulators of tissue homeostasis that govern cellular function and development, by transducing adhesive signals to a complex network of signaling effectors and transcriptional programs [56]. Specifically, CDH1 and M-cadherin (CDH15) are calciumdependent intercellular adhesion molecules. $C D H 1$ played an important role in epithelial adhesion, geometrical packing and Spatial effort $[57,58]$. We suspect $C D H 15$ has a similar function; Claudins as the cell adhesion protein are members of the membrane-associated guanylate kinases (MAGUK) family proteins and the main bridge proteins of connecting claudins with the underlying actin cytoskeleton [59]. Studies found that the formation of adhesion junctions could also promote tight junction assembly by altering the lipid composition of the plasma membrane. Low $\mathrm{Ca}^{2+}$ led to internalization of claudins and reduced cholesterol in the plasma membrane [60]. This suggested that $\mathrm{Ca}^{2+}$ concentration and the genes involved in cell adhesion might be related to the shedding of epithelial cells in the crop of lactating pigeon. Other genes involved in cell adhesion played a major role in the immune system and neural system, majorly participating in $\mathrm{T}$ cell receptor signaling pathway, inducing $\mathrm{T}$ cell activation and differentiation [61].

Regarding the constructed miRNA-associated-ceRNA networks, we desired to explore the roles of key RNA molecules in crop milk formation and epithelial cell morphogenesis. We found that many genes were identified as predicted target genes of miRNAs that might play critical roles in metabolism through several pathways. So HADHA, adrenoceptor $\beta 3$ (ADRB3), ACACA, ELOVL6, and 7-dehydrocholesterol reductase (DHCR7) were identified as key genes for lipid and fatty acid metabolism. The product of $A C A C A$ is the rate-limiting enzyme in the biosynthesis of long-chain fatty acids and was reported to be an important enzyme involved in the synthesis of saturated fatty acids. This enzyme was expressed 
ubiquitously, but the highest level was found in lipogenic tissues such as the liver, adipose tissue and lactating mammary gland [62-64]. Similarly, ADRB3 was a key gene in the process of adipose tissue browning and was reportedly down-regulated in adipocytes of obese people [65]. This allowed researchers to focus on adipose tissue browning in mice [66] and humans $[67,68]$. In this study, $A D R B 3$ was downregulated in lactating pigeon crop, corresponding to the period of a high proportion of fat (33.8\%) in crop milk [4]. Both HADHA and DHCR7 have been shown to be involved in lipid processes, including cardiolipin re-modeling, fatty acid $\beta$-Oxidation in human myocardium [69] and vitamin D-lipid interaction [70], respectively. Seven members of the ELOVL protein family have been described in mammals [71,72]. They are closely related to fatty acid metabolism and hepatic insulin sensitivity. ELOVL fatty acid elongase 4 (ELOVL4), ELOVL fatty acid elongase 5 (ELOVL5), ELOVL6, and ELOVL fatty acid elongase 7 (ELOVL7) were differentially expressed and identified in the crop tissues of lactating and non-lactating pigeons in our previous study [28]. However, only ELOVL6 appeared in the ceRNA network in the current study. ELOVL4 could be capable of elongating both saturated fatty acids and polyunsaturated fatty acid (PUFA) [71] and was responsible for the biosynthesis of saturated very long-chain fatty acids (VLC-FA) that are components of sphingolipids and ceramides and are important in the skin [73,74]. ELOVL6 and ELOVL7 can catalyze the elongation of saturated and monounsaturated fatty acids in mammals. ELOVL6 deficiency in mouse livers changes the composition of liver fatty acids, the length of the fatty acid chain, and the ratio of fatty acids, with a consequent reduction of SREBP-1 and PPAR $\alpha$ in the liver. Decreased expression of $S R E B P-1$ reduced fatty acid synthesis, but increased insulin sensitivity [75]. In this study, ELOVL6 was up-regulated in the crop of lactating pigeon, suggesting that it may be involved in fat synthesis.

It has been established that crop milk was formed mainly from proliferation and shedding of a large number of epithelial cells in the crop tissue. Indian Hedgehog $(I H H)$ could regulate formation and proliferation of mesenchymal cells, which in turn affect epithelial proliferation and differentiation in intestinal epithelial cell [76]. Grainy head-like transcription factor 2 (GRHL2) was a member of grainy head-like transcription family, which played a fundamental role in epidermal integrity, embryonic neural tube closure, and wound healing processes [77,78]. ESRP2 protein was reported to regulate alternative splicing in epithelial cells $[79,80]$. Its loss disrupted the splicing of the transcripts from genes, thereby losing the ability to form sheets of cells with junctions between them [81]. In addition, ESRP2 and microtubule-associated serine/threonine kinase like (MASTL) clustered with epithelial markers and correlated inversely with the expression of mesenchymal markers [79,81]. EMT could activate a molecular program that drives epithelial cells to acquire mesenchymal phenotypes; it usually ends with the transition from mesenchymal to epithelial (MET). This state transition was very flexible [82]. Interestingly, this seems to be similar to the transformation between lactating and non-lactating crop tissues, and we infer that the ESRP2 gene was transformed between lactating and non-lactating crop tissues during the two periods. More importantly, in many cancers, the property of tumor dissemination and metastasis is closely associated with re-enabling developmental properties such as EMT [83]. These results indicated that the formation of crop milk is related to the transformation of cell morphology. Kinesin family member 26B (KIF26B) stabilized the cell-cell adhesion of mesenchymal cells in the developing kidney through enhancing the interaction of NMHC II and actin [84]. DOT1L between renal fibroblast activation and epithelial mesenchymal played a role in the process of transformation [85]. Phosphatidylinositol-3-kinase (PI3K) was a key signaling hub in immune cells. Either too little or too much PI3K activity was deleterious [86]. Mutations, activation, and low expression of PIK3CD were associated with autoimmune diseases and immunodeficiency $[87,88]$.

In summary, a regulatory network was constructed. The regulatory relationship of these key genes has been listed and could be used as a key research object to further explain the production mechanism of crop milk. However, a limitation of this study is that most of the ceRNA networks identified were largely based on correlation analysis. Further 
strong evidence should be obtained to fully elucidate the identified ceRNA regulatory networks. Collectively, our study offered new insight for the ceRNA regulatory in crop milk production.

\section{Conclusions}

MiRNAs were abundant in the pigeon crop. Substance synthesis and cell morphogenesis genes remained active in lactation under the miRNA-associated-ceRNA regulation. Our findings enriched the pigeon miRNA expression profile and provide novel insights into the miRNA-associated ceRNA expression pattern and regulatory roles in crop milk production.

Supplementary Materials: Supplementary materials can be found at https://www.mdpi.com/20 73-4425/12/1/39/s1. Table S1: Primers of lncRNAs and mRNAs used in qRT-PCR. Table S2: The annotation file of Small RNA. Table S3: The information of Novel RNA. Table S4: The TPM value of miRNA. Table S5: The differential expression of miRNA. Table S6: The GO terms of enriched. Table S7: The KEGG pathway of enriched. Table S8: The information of protein interactions.

Author Contributions: Conceptualization, H.M. and J.C.; Writing-original draft, P.G., Y.L. and H.M.; Funding acquisition, J.C. and H.M.; Visualization and Software, P.G. and Y.L.; Writing-review \& editing A.N., A.M.I. and P.W.; Software, S.B. and L.S. Resources, Y.Z., Y.W., L.J. and H.H. Methodology, J.Y. and Y.S. All authors have read and agreed to the published version of the manuscript.

Funding: This research was funded by 1. National Natural Science Foundation of China (31802058), 2. Beijing Innovation Consortium of Agriculture System (BAIC04-2020), 3. National Key Research and Development Program of China (2019-YWF-YB-12) and 4. Agricultural Science and Technology Innovation Program (ASTIPIAS04).

Informed Consent Statement: Not applicable.

Conflicts of Interest: The authors declare no conflict of interest.

\begin{tabular}{|c|c|}
\hline \multicolumn{2}{|c|}{ Abbreviations } \\
\hline MRES & miRNA response elements \\
\hline GO & Gene ontology \\
\hline KEGG & Kyoto encyclopedia of genes and genomes \\
\hline ceRNA & Competing endogenous RNA \\
\hline HPRT1 & Hypoxanthine phosphoribosyltransferase 1 \\
\hline DEGs & differentially expressed genes \\
\hline PPI & Protein protein interaction \\
\hline EPRS & Glutamyl-prolyl tRNA synthetase \\
\hline SREBF1 & Sterol regulatory element-binding protein 1 \\
\hline$A C A C A$ & Acetyl-CoA carboxylase $\alpha$ \\
\hline PPP1CA & Protein phosphatase type $1 \alpha$ \\
\hline CREBRF & CREB3 regulatory factor \\
\hline ELOVL4 & ELOVL fatty acid elongase 4 \\
\hline ELOVL5 & ELOVL fatty acid elongase 5 \\
\hline ELOVL6 & ELOVL fatty acid elongase 6 \\
\hline ELOVL7 & ELOVL fatty acid elongase 7 \\
\hline$H G F$ & Hepatocyte growth factor \\
\hline$L A M C 2$ & Laminin subunit $\gamma 2$ \\
\hline ITGB8 & Integrin subunit $\beta 8$ \\
\hline PDGFRB & Platelet derived growth factor receptor $\beta$ \\
\hline$A D R B 1$ & Adrenoceptor $\beta 1$ \\
\hline PIK3CD & Phosphatidylinositol-4,5-bisphosphate 3-kinase catalytic subunit delta \\
\hline $\mathrm{CDH1}$ & E-cadherin \\
\hline DOT1L & DOT1 like histone lysine methyltransferase \\
\hline ESRP2 & Epithelial splicing regulatory protein 2 \\
\hline TTC28 & Tetratricopeptide repeat domain 28 \\
\hline IGF2 & Insulin-like growth factor 2 \\
\hline
\end{tabular}




$\begin{array}{ll}\text { CDH15 } & \text { M-cadherin } \\ \text { MAGUK } & \text { Membrane associated guanylate kinases } \\ \text { ADRB3 } & \text { Adrenoceptor } \beta 3 \\ \text { DHCR7 } & \text { 7-dehydrocholesterol reductase } \\ \text { IHH } & \text { Indian Hedgehog Regulates } \\ \text { GRHL2 } & \text { Grainy head like transcription factor 2 } \\ \text { EMT } & \text { Epithelial mesenchymal transition } \\ \text { MET } & \text { Mesenchymal epithelial transition } \\ \text { KIF26B } & \text { Kinesin family member 26B } \\ \text { PUFA } & \text { polyunsaturated fatty acid } \\ \text { VLC-FA } & \text { very long-chain fatty acids }\end{array}$

\section{References}

1. Anderson, T.R.; Pitts, D.S.; Nicoll, C.S. Prolactin's mitogenic action on the pigeon crop-sac mucosal epithelium involves direct and indirect mechanisms. Gen. Comp. Endocrinol. 1984, 54, 236-246. [CrossRef]

2. Griminger, P. Physiology and Behaviour of the Pigeon; Academic Press: London, UK, 1983.

3. Horseman, N.D.; Buntin, J.D. Regulation of pigeon cropmilk secretion and parental behaviors by prolactin. Annu. Rev. Nutr. 1995, 15, 213-238. [CrossRef]

4. Davies, W.L. The composition of the crop milk of pigeons. Biochem. J. 1939, 33, 898-901. [CrossRef]

5. Bharathi, L.; Shenoy, K.B.; Mojamdar, M.; Hegde, S.N. In vitro growth-stimulatory property of pigeon milk. Biochem. Cell Biol. 1993, 71, 303-307. [CrossRef]

6. Desmeth, M.V.J. Lipid composition of pigeon cropmilk-I. Total lipids and lipid classes. Comp. Biochem. Physiol. Part B 1980, 1, 129-133. [CrossRef]

7. Shetty, S.; Hegde, S.N. Stimulatory effect of pigeon milk growth factor on protein and nucleic acid synthesis in neonate mice. Biol. Neonate 1992, 62, 409-415. [CrossRef]

8. Hegde, S.N. A note on the comparative weight increase in the nidicolous pigeon squab and the nidifugous domestic chick during the first four postnatal weeks. Indian Zool 1970, 1, 1-6.

9. Hegde, S.N. The composition of pigeon milk and its effects on growth in chicks. Ind. J. Exp. Biol. 1973, 11, 238-239.

10. Shetty, S.; Hegde, S.N. Pigeon milk: A new source of growth factor. Experientia 1993, 49, 925-928. [CrossRef] [PubMed]

11. Bharathi, L.; Shenoy, K.B.; Hegde, S.N. In vivo and in vitro growth-stimulatory effects of pigeon milk. Comp. Biochem. Physiol. Comp. Physiol. 1994, 108, 451-459. [CrossRef]

12. König, H.E.; Korbel, R.; Liebich, H. Avian Anatomy; 5M Publishing Ltd., 8 Smithy Wood Drive: Sheffield, UK, 2016.

13. Hu, X.C.; Gao, C.Q.; Wang, X.H.; Yan, H.C.; Chen, Z.S.; Wang, X.Q. Crop milk protein is synthesised following activation of the IRS1/Akt/TOR signalling pathway in the domestic pigeon (Columba livia). Br. Poult. Sci. 2016, 57, 855-862. [CrossRef] [PubMed]

14. Chen, M.J.; Fu, Z.; Jiang, S.G.; Wang, X.Q.; Yan, H.C.; Gao, C.Q. Targeted disruption of TORC1 retards young squab growth by inhibiting the synthesis of crop milk protein in breeding pigeon (Columba livia). Poult. Sci. 2019, 99, 416-422. [CrossRef] [PubMed]

15. Xie, W.Y.; Fu, Z.; Pan, N.X.; Yan, H.C.; Wang, X.Q.; Gao, C.Q. Leucine promotes the growth of squabs by increasing crop milk protein synthesis through the TOR signaling pathway in the domestic pigeon (Columba livia). Poult. Sci. 2019, 98, 5514-5524. [CrossRef]

16. Xie, P.; Wang, X.P.; Bu, Z.; Zou, X.T. Differential expression of fatty acid transporters and fatty acid synthesis-related genes in crop tissues of male and female pigeons (Columba livia domestica) during incubation and chick rearing. Br. Poult. Sci. 2017, 58, 594-602. [CrossRef] [PubMed]

17. Gillespie, M.J.; Crowley, T.M.; Haring, V.R.; Wilson, S.L.; Harper, J.A.; Payne, J.S.; Green, D.; Monaghan, P.; Stanley, D.; Donald, J.A.; et al. Transcriptome analysis of pigeon milk production-Role of cornification and triglyceride synthesis genes. BMC Genom. 2013, 14, 169. [CrossRef]

18. Salmena, L.; Poliseno, L.; Tay, Y.; Kats, L.; Pandolfi, P.P. A ceRNA hypothesis: The Rosetta Stone of a hidden RNA language? Cell 2011, 146, 353-358. [CrossRef]

19. Thomson, D.W.; Dinger, M.E. Endogenous microRNA sponges: Evidence and controversy. Nat. Rev. Genet. 2016, 17, 272-283. [CrossRef]

20. Bartel, D.P. MicroRNAs: Target recognition and regulatory functions. Cell 2009, 136, 215-233. [CrossRef]

21. Thomas, M.; Lieberman, J.; Lal, A. Desperately seeking microRNA targets. Nat. Struct. Mol. Biol. 2010, 17, 1169-1174. [CrossRef]

22. Peng, J.; Zhao, J.S.; Shen, Y.F.; Mao, H.G.; Xu, N.Y. MicroRNA expression profiling of lactating mammary gland in divergent phenotype swine breeds. Int. J. Mol. Sci. 2015, 16, 1448-1465. [CrossRef]

23. Wang, M.; Moisá, S.; Khan, M.J.; Wang, J.; Bu, D.; Loor, J.J. MicroRNA expression patterns in the bovine mammary gland are affected by stage of lactation. J. Dairy Sci. 2012, 95, 6529-6535. [CrossRef] [PubMed]

24. Avril-Sassen, S.; Goldstein, L.D.; Stingl, J.; Blenkiron, C.; Le Quesne, J.; Spiteri, I.; Karagavriilidou, K.; Watson, C.J.; Tavaré, S.; Miska, E.A.; et al. Characterisation of microRNA expression in post-natal mouse mammary gland development. BMC Genom. 2009, 10, 548. [CrossRef] [PubMed] 
25. Ucar, A.; Vafaizadeh, V.; Jarry, H.; Fiedler, J.; Klemmt, P.A.; Thum, T.; Groner, B.; Chowdhury, K. miR-212 and miR-132 are required for epithelial stromal interactions necessary for mouse mammary gland development. Nat. Genet. 2010, 42, 1101-1108. [CrossRef] [PubMed]

26. Lee, M.J.; Yoon, K.S.; Cho, K.W.; Kim, K.S.; Jung, H.S. Expression of miR-206 during the initiation of mammary gland development. Cell Tissue Res. 2013, 353, 425-433. [CrossRef]

27. Manjarín, R.; Steibel, J.P.; Kirkwood, R.N.; Taylor, N.P.; Trottier, N.L. Transcript abundance of hormone receptors, mammalian target of rapamycin pathway-related kinases, insulin-like growth factor I, and milk proteins in porcine mammary tissue. J. Anim. Sci. 2012, 90, 221-230. [CrossRef]

28. Ma, H.; Ni, A.; Ge, P.; Li, Y.; Shi, L.; Wang, P.; Fan, J.; Isa, A.M.; Sun, Y.; Chen, J. Analysis of Long Non-Coding RNAs and mRNAs Associated with Lactation in the Crop of Pigeons (Columba livia). Genes 2020, 11, 201. [CrossRef]

29. Kim, D.; Paggi, J.M.; Park, C.; Bennett, C.; Salzberg, S.L. Graph-based genome alignment and genotyping with HISAT2 and HISAT-genotype. Nat. Biotechnol. 2019, 37, 907-915. [CrossRef]

30. Pertea, M.; Kim, D.; Pertea, G.M.; Leek, J.T.; Salzberg, S.L. Transcript-level expression analysis of RNA-seq experiments with HISAT, StringTie and Ballgown. Nat. Protoc. 2016, 11, 1650. [CrossRef]

31. Langmead, B.; Trapnell, C.; Pop, M.; Salzberg, S.L. Ultrafast and memory efficient alignment of short DNA sequences to the human genome. Genome. Biol. 2009, 10, R25. [CrossRef]

32. Kozomara, A.; Griffiths-Jones, S. miRBase: Annotating high confidence microRNAs using deep sequencing data. Nucleic Acids Res. 2014, 42, D68-D73. [CrossRef]

33. Kalvari, I.; Argasinska, J.; Quinones-Olvera, N.; Nawrocki, E.P.; Rivas, E.; Eddy, S.R.; Bateman, A.; Finn, R.D.; Petrov, A.I. Rfam 13.0: Shifting to a genome-centric resource for non-coding RNA families. Nucleic Acids Res. 2018, 46, D335-D342. [CrossRef] [PubMed]

34. Friedländer, M.R.; Mackowiak, S.D.; Li, N.; Chen, W.; Rajewsky, N. miRDeep2 accurately identifies known and hundreds of novel microRNA genes in seven animal clades. Nucleic Acids Res. 2012, 40, 37-52. [CrossRef] [PubMed]

35. Love, M.I.; Huber, W.; Anders, S. Moderated estimation of fold change and dispersion for RNA-seq data with DESeq2. Genome. Biol. 2014, 15, 550. [CrossRef] [PubMed]

36. Kertesz, M.; Iovino, N.; Unnerstall, U.; Gaul, U.; Segal, E. The role of site accessibility in microRNA target recognition. Nat. Genet. 2007, 39, 1278-1284. [CrossRef]

37. Enright, A.J.; John, B.; Gaul, U.; Tuschl, T.; Sander, C.; Marks, D.S. MicroRNA targets in Drosophila. Genome. Biol. 2003,5 , R1. [CrossRef]

38. Agarwal, V.; Bell, G.W.; Nam, J.W.; Bartel, D.P. Predicting effective microRNA target sites in mammalian mRNAs. eLife 2015, 4, e05005. [CrossRef]

39. Gillespie, M.J.; Haring, V.R.; McColl, K.A.; Monaghan, P.; Donald, J.A.; Nicholas, K.R.; Moore, R.J.; Crowley, T.M. Histological and global gene expression analysis of the 'lactating' pigeon crop. BMC Genom. 2011, 12, 452. [CrossRef]

40. Chen, X.; Zheng, Y.; Li, X.; Gao, Q.; Feng, T.; Zhang, P.; Liao, M.; Tian, X.E.; Lu, H.; Zeng, W. Profiling of miRNAs in porcine Sertoli cells. J. Anim. Sci. Biotechnol. 2020, 11, 85. [CrossRef]

41. Aryal, B.; Singh, A.K.; Rotllan, N.; Price, N.; Fernández-Hernando, C. MicroRNAs and lipid metabolism. Curr. Opin. Lipidol. 2017, 28, 273-280. [CrossRef]

42. Goody, D.; Pfeifer, A. MicroRNAs in brown and beige fat. Biochim. Biophys. Acta Mol. Cell Biol. Lipids 2019, 1864, 29-36. [CrossRef]

43. Litwer, G. Die Histologischen Veränderungen der Kropfwandung beiTauben, zur Zeit der Bebrütung und Ausfütterung ihrer Jungen. Z. Zellforsch. Mikrosk. Anat. 1926, 3, 695-722. [CrossRef]

44. Weber, W. Zur Histologie und Cytologie der Kropfmilchbildung derTaube. Z. Zellforsch. Mikrosk. Anat. 1962, 56, 247-276. [CrossRef]

45. Qi, J.; Yang, Z.; Zhang, Y.; Lu, B.; Yin, Y.; Liu, K.; Xue, W.; Qu, C.; Li, W. miR-20b-5p, TGFBR2, and E2F1 Form a Regulatory Loop to Participate in Epithelial to Mesenchymal Transition in Prostate Cancer. Front. Oncol. 2020, 9, 1535. [CrossRef] [PubMed]

46. Al-Ansari, M.M.; Aboussekhra, A. miR-146b-5p mediates p16-dependent repression of IL-6 and suppresses paracrine procarcinogenic effects of breast stromal fibroblasts. Oncotarget 2015, 6, 30006-30016. [CrossRef]

47. Lee, J.H.; Kim, S.W.; Han, J.S.; Shin, S.P.; Lee, S.I.; Park, T.S. Functional analyses of miRNA-146b-5p during myogenic proliferation and differentiation in chicken myoblasts. BMC Mol. Cell Biol. 2020, 21, 40. [CrossRef]

48. Cai, M.; Shao, W.; Yu, H.; Hong, Y.; Shi, L. Paeonol Inhibits Cell Proliferation, Migration and Invasion and Induces Apoptosis in Hepatocellular Carcinoma by Regulating miR-21-5p/KLF6 Axis. Cancer Manag. Res. 2020, 12, 5931-5943. [CrossRef]

49. Yang, Z.; Liao, B.; Xiang, X.; Ke, S. miR-21-5p promotes cell proliferation and G1/S transition in melanoma by targeting CDKN2C. FEBS Open Bio 2020, 10, 752-760. [CrossRef]

50. Yan, L.; Ma, J.; Wang, Y.; Zan, J.; Wang, Z.; Zhu, Y.; Zhu, Y.; Ling, L.; Cao, L.; Liu, X.; et al. miR-21-5p induces cell proliferation by targeting TGFBI in non-small cell lung cancer cells. Exp. Ther. Med. 2018, 16, 4655-4663. [CrossRef]

51. Yu, W.; Zhu, K.; Wang, Y.; Yu, H.; Guo, J. Overexpression of miR-21-5p promotes proliferation and invasion of colon adenocarcinoma cells through targeting CHL1. Mol. Med. 2018, 24, 36. [CrossRef]

52. Yi, F.; Shang, Y.; Li, B.; Dai, S.; Wu, W.; Cheng, L.; Wang, X. MicroRNA-193-5p modulates angiogenesis through IGF2 in type 2 diabetic cardiomyopathy. Biochem. Biophys. Res. Commun. 2017, 491, 876-882. [CrossRef] 
53. Luo, Y.; Ji, H.; Cao, Y.; Ding, X.; Li, M.; Song, H.; Li, S.; WaTableng, C.; Wu, H.; Meng, J.; et al. miR-26b-5p/TCF-4 Controls the Adipogenic Differentiation of Human Adipose-derived Mesenchymal Stem Cells. Cell Transplant. 2020, 29, 963689720934418. [CrossRef] [PubMed]

54. Arif, A.; Terenzi, F.; Potdar, A.A.; Jia, J.; Sacks, J.; China, A.; Halawani, D.; Vasu, K.; Li, X.; Brown, J.M.; et al. EPRS is a critical mTORC1-S6K1 effector that influences adiposity in mice. Nature 2017, 542, 357-361. [CrossRef] [PubMed]

55. Lin, Y.; Ding, D.; Huang, Q.; Liu, Q.; Lu, H.; Lu, Y.; Chi, Y.; Sun, X.; Ye, G.; Zhu, H.; et al. Downregulation of miR-192 causes hepatic steatosis and lipid accumulation by inducing SREBF1: Novel mechanism for bisphenol A-triggered non-alcoholic fatty liver disease. Biochim. Biophys. Acta Mol. Cell Biol. Lipids 2017, 1862, 869-882. [CrossRef]

56. Bruner, H.C.; Derksen, P. Loss of E-Cadherin-Dependent Cell-Cell Adhesion and the Development and Progression of Cancer. Cold Spring Harb. Perspect. Biol. 2018, 10, a029330. [CrossRef]

57. Mohan, A.; Schlue, K.T.; Kniffin, A.F.; Mayer, C.R.; Duke, A.A.; Narayanan, V.; Arsenovic, P.T.; Bathula, K.; Danielsson, B.E.; Dumbali, S.P.; et al. Spatial Proliferation of Epithelial Cells Is Regulated by E-Cadherin Force. Biophys. J. 2018, 115, 853-864. [CrossRef]

58. Hildebrand, S.; Hultin, S.; Subramani, A.; Petropoulos, S.; Zhang, Y.; Cao, X.; Mpindi, J.; Kalloniemi, O.; Johansson, S.; Majumdar, A.; et al. The E-cadherin/AmotL2 complex organizes actin filaments required for epithelial hexagonal packing and blastocyst hatching. Sci. Rep. 2017, 7, 9540. [CrossRef]

59. Shigetomi, K.; Ikenouchi, J. Cell Adhesion Structures in Epithelial Cells Are Formed in Dynamic and Cooperative Ways. Bioessays 2019, 41, e1800227. [CrossRef]

60. Shigetomi, K.; Ono, Y.; Inai, T.; Ikenouchi, J. Adherens junctions influence tight junction formation via changes in membrane lipid composition. J. Cell Biol. 2018, 217, 2373-2381. [CrossRef]

61. Dailey, M.O. Expression of T lymphocyte adhesion molecules: Regulation during antigen-induced T cell activation and differentiation. Crit. Rev. Immunol. 1998, 18, 153-184. [CrossRef]

62. Federica, S.; Francesco, N.; Giovanna, D.M.; Carmela, S.M.; Gennaro, C.; Carmela, T.; Bianca, M. Identification of novel single nucleotide polymorphisms in promoter III of the acetyl-CoA carboxylase-\{alpha\} gene in goats affecting milk production traits. $J$. Hered. 2009, 100, 386-389. [CrossRef]

63. Moioli, B.; Scatà, M.C.; De Matteis, G.; Annicchiarico, G.; Catillo, G.; Napolitano, F. The ACACA gene is a potential candidate gene for fat content in sheep milk. Anim. Genet. 2013, 44, 601-603. [CrossRef] [PubMed]

64. Barber, M.C.; Clegg, R.A.; Travers, M.T.; Vernon, R.G. Lipid metabolism in the lactating mammary gland. Biochim. Biophys. Acta (BBA)-Lipids Lipid Metab. 1997, 1347, 101-126. [CrossRef]

65. Cao, W.; Liu, Z.; Guo, F.; Yu, J.; Li, H.; Yin, X. Adipocyte ADRB3 Down-Regulated in Chinese Overweight Individuals Adipocyte ADRB3 in Overweight. Obes. Facts 2018, 11, 524-533. [CrossRef]

66. Lee, Y.H.; Petkova, A.P.; Mottillo, E.P.; Granneman, J.G. In vivo identification of bipotential adipocyte progenitors recruited by ß3-adrenoceptor activation and high-fat feeding. Cell Metab. 2012, 15, 480-491. [CrossRef]

67. Bordicchia, M.; Pocognoli, A.; D’Anzeo, M.; Siquini, W.; Minardi, D.; Muzzonigro, G.; Dessì-Fulgheri, P.; Sarzani, R. Nebivolol induces, via $\beta 3$ adrenergic receptor, lipolysis, uncoupling protein 1 , and reduction of lipid droplet size in human adipocytes. J. Hypertens 2014, 32, 389-396. [CrossRef]

68. Cypess, A.M.; Weiner, L.S.; Roberts-Toler, C.; Franquet, E.E.; Kessler, S.H.; Kahn, P.A.; English, J.; Chatman, K.; Trauger, S.A.; Doria, A.; et al. Activation of human brown adipose tissue by a $\beta 3$-adrenergic receptor agonist. Cell Metab. 2015, $21,33-38$. [CrossRef]

69. Miklas, J.W.; Clark, E.; Levy, S.; Detraux, D.; Leonard, A.; Beussman, K.; Showalter, M.R.; Smith, A.T.; Hofsteen, P.; Yang, X.; et al. $\mathrm{TFPa} / \mathrm{HADHA}$ is required for fatty acid beta-oxidation and cardiolipin re-modeling in human cardiomyocytes. Nat. Commun. 2019, 10, 4671. [CrossRef]

70. Rodríguez-Carrio, J.; Alperi-López, M.; Naves-Díaz, M.; Dusso, A.; López, P.; Ballina-García, F.J.; Cannata-Andía, J.B.; Suárez, A. Vitamin D Receptor Polymorphism and DHCR7 Contribute to the Abnormal Interplay Between Vitamin D and Lipid Profile in Rheumatoid Arthritis. Sci. Rep. 2019, 9, 2546. [CrossRef]

71. Jakobsson, A.; Westerberg, R.; Jacobsson, A. Fatty acid elongases in mammals: Their regulation and roles in metabolism. Prog. Lipid Res. 2006, 45, 237-249. [CrossRef]

72. Guillou, H.; Zadravec, D.; Martin, P.G.; Jacobsson, A. The key roles of elongases and desaturases in mammalian fatty acid metabolism: Insights from transgenic mice. Prog. Lipid Res. 2010, 49, 186-199. [CrossRef]

73. Cameron, D.J.; Tong, Z.; Yang, Z.; Kaminoh, J.; Kamiyah, S.; Chen, H.; Zeng, J.; Chen, Y.; Luo, L.; Zhang, K. Essential role of Elovl4 in very long chain fatty acid synthesis, skin permeability barrier function, and neonatal survival. Int. J. Biol. Sci. 2007, 3, 111-119. [CrossRef]

74. Li, W.; Sandhoff, R.; Kono, M.; Zerfas, P.; Hoffmann, V.; Ding, B.C.; Proia, R.L.; Deng, C.X. Depletion of ceramides with very long chain fatty acids causes defective skin permeability barrier function, and neonatal lethality in ELOVL4 deficient mice. Int. J. Biol. Sci. 2007, 3, 120-128. [CrossRef]

75. Matsuzaka, T.; Shimano, H. Elovl6: A new player in fatty acid metabolism and insulin sensitivity. J. Mol. Med. 2009, 87, 379-384. [CrossRef] 
76. Kosinski, C.; Stange, D.E.; Xu, C.; Chan, A.S.; Ho, C.; Yuen, S.T.; Mifflin, R.C.; Powell, D.W.; Clevers, H.; Leung, S.Y.; et al. Indian hedgehog regulates intestinal stem cell fate through epithelial-mesenchymal interactions during development. Gastroenterology 2010, 139, 893-903. [CrossRef]

77. Boglev, Y.; Wilanowski, T.; Caddy, J.; Parekh, V.; Auden, A.; Darido, C.; Hislop, N.R.; Cangkrama, M.; Ting, S.B.; Jane, S.M. The unique and cooperative roles of the Grainy head-like transcription factors in epidermal development reflect unexpected target gene specificity. Dev. Biol. 2011, 349, 512-522. [CrossRef]

78. Chung, V.Y.; Tan, T.Z.; Tan, M.; Wong, M.K.; Kuay, K.T.; Yang, Z.; Ye, J.; Muller, J.; Koh, C.M.; Guccione, E.; et al. GRHL2-miR-200ZEB1 maintains the epithelial status of ovarian cancer through transcriptional regulation and histone modification. Sci. Rep. 2016, 6, 19943. [CrossRef]

79. Warzecha, C.C.; Sato, T.K.; Nabet, B.; Hogenesch, J.B.; Carstens, R.P. ESRP1 and ESRP2 are epithelial cell-type-specific regulators of FGFR2 splicing. Mol. Cell 2009, 33, 591-601. [CrossRef]

80. Bebee, T.W.; Park, J.W.; Sheridan, K.I.; Warzecha, C.C.; Cieply, B.W.; Rohacek, A.M.; Xing, Y.; Carstens, R.P. The splicing regulators Esrp1 and Esrp2 direct an epithelial splicing program essential for mammalian development. eLife 2015, 4, e08954. [CrossRef]

81. Sun, X.J.; Li, Y.L.; Wang, L.G.; Liu, L.Q.; Ma, H.; Hou, W.H.; Yu, J.M. Mastl overexpression is associated with epithelial to mesenchymal transition and predicts a poor clinical outcome in gastric cancer. Oncol. Lett. 2017, 14, 7283-7287. [CrossRef]

82. Simeone, P.; Trerotola, M.; Franck, J.; Cardon, T.; Marchisio, M.; Fournier, I.; Salzet, M.; Maffia, M.; Vergara, D. The multiverse nature of epithelial to mesenchymal transition. Semin. Cancer Biol. 2019, 58, 1-10. [CrossRef]

83. Antony, J.; Thiery, J.P.; Huang, R.Y. Epithelial-to-mesenchymal transition: Lessons from development, insights into cancer and the potential of EMT-subtype based therapeutic intervention. Phys. Biol. 2019, 16, 041004. [CrossRef]

84. Uchiyama, Y.; Sakaguchi, M.; Terabayashi, T.; Inenaga, T.; Inoue, S.; Kobayashi, C.; Oshima, N.; Kiyonari, H.; Nakagata, N.; Sato, Y.; et al. Kif26b, a kinesin family gene, regulates adhesion of the embryonic kidney mesenchyme. Proc. Natl. Acad. Sci. USA 2010, 107, 9240-9245. [CrossRef]

85. Liu, L.; Zou, J.; Guan, Y.; Zhang, Y.; Zhang, W.; Zhou, X.; Xiong, C.; Tolbert, E.; Zhao, T.C.; Bayliss, G.; et al. Blocking the histone lysine 79 methyltransferase DOT1L alleviates renal fibrosis through inhibition of renal fibroblast activation and epithelial-mesenchymal transition. FASEB J. 2019, 33, 11941-11958. [CrossRef]

86. Tangye, S.G.; Bier, J.; Lau, A.; Nguyen, T.; Uzel, G.; Deenick, E.K. Immune Dysregulation and Disease Pathogenesis due to Activating Mutations in PIK3CD-the Goldilocks' Effect. J. Clin. Immunol. 2019, 39, 148-158. [CrossRef]

87. Bier, J.; Rao, G.; Payne, K.; Brigden, H.; French, E.; Pelham, S.J.; Lau, A.; Lenthall, H.; Edwards, E.; Smart, J.M.; et al. Activating mutations in PIK3CD disrupt the differentiation and function of human and murine CD4(+) T cells. J. Allergy Clin. Immunol. 2019, 144, 236-253. [CrossRef]

88. Kiyota, K.; Yoshiura, K.I.; Houbara, R.; Miyahara, H.; Korematsu, S.; Ihara, K. Auto-immune disorders in a child with PIK3CD variant and 22q13 deletion. Eur. J. Med. Genet. 2018, 61, 631-633. [CrossRef] 